\title{
MENGOPTIMALKAN LALU-LINTAS PERBELANJAAN DENGAN MENGATUR DERAJAT KEPENTINGAN ANTAR ETALASE
}

\author{
Hendy Tannady Tan \\ Department of Industrial Engineering, Faculty of Engineering, Universitas Bina Nusantara \\ Jl. K. H. Syahdan No. 9 Palmerah Jakarta Barat 11480 \\ hendy_tan3003@yahoo.com
}

\begin{abstract}
The high rate of retail industry growth absolutely needs good attention and well-constructive improvement. We often see that the consumer waste their time to shop in super market. With Data Mining and its relation with association function, it is expected to give inputs and contribution for the revolution of placing procedure of display case layout in every retail businesses, either in big supermarket or the small one. The result of this research is that the association pattern was gained among several display-case objects, and the distance between display cases is the determined variable of the implementation of association tabulation.
\end{abstract}

Keywords: retail, layout, association

\begin{abstract}
ABSTRAK
Besarnya laju pertumbuhan industri ritel tentunya perlu mendapat perhatian dan improvisasi yang baik dan konstruktif. Banyak waktu yang dibutuhkan seorang konsumen untuk berbelanja di sebuah pasar swalayan. Dengan Data Mining dan melihat kaitannya dengan fungsi Asosiasi diharapkan mampu memberikan masukan dan kontribusi bagi revolusi tata cara penempatan layout etalase di setiap usaha ritel, baik itu pasar swalayan besar maupun kecil. Hasil dari penelitian ini adalah diperolehnya pola asosiasi di antara beberapa obyek etalase, dan jarak antar etalase merupakan variabel penentu dari implementasi tabulasi asosiasi.
\end{abstract}

Kata kunci: ritel, layout, asosiasi 


\section{PENDAHULUAN}

Saat ini di Indonesia atau Jakarta pada khususnya telah berkembang dengan pesat bisnis pusat perbelanjaan, saat ini banyak pemain baru telah bermunculan, seperti Lotte Mart dan TESCO raja bisnis perbelanjaan dari Inggris pun mulai ingin masuk pada pasar Asia Tenggara, belum lagi ditambah dengan pemain lama yang telah aral melintang menjalani bisnis ini di tanah air. Dengan semakin banyaknya usaha serupa, mengindikasikan bahwa usaha tempat perbelanjaan di Indonesia merupakan usaha yang termasuk kategori Red Ocean, di mana persaingan yang terjadi sudah sedemikian pesat dan banyaknya sehingga pemain dengan modal dan keahlian strategi bisnis yang tidak cukup memadai akan mudah sekali lenyap dari persaingan.

Pasar Swalayan XYZ cabang Puri merupakan tempat perbelanjaan swalayan modern yang cukup ramai dan telah mendapat tempat di hati konsumen yang bertempat tinggal di daerah Puri, Kembangan, Meruya, Taman Semanan dan sekitarnya. Selain itu XYZ saat ini juga aktif untuk terus berekspansi memperluas cabangnya ke seantero nusantara. Pada hari Sabtu dan Minggu XYZ sangat ramai dikunjungi pembeli. Dapat menjumpai betapa padatnya lalu-lintas di dalam XYZ pada hari Sabtu dan Minggu. Tentunya kondisi ini sangat membuat tidak nyaman dalam berbelanja. Pada penelitian ini dicoba untuk membuat semacam simulasi dari etalase-etalase yang ada, diharapkan setelah posisi dan urutan etalase kita tata akan tercipta kondisi lalu-lintas yang lebih nyaman.

Untuk mengetahui lebih detail mengenai permasalahan yang terjadi, dilakukan survey mengenai Consumer habit dalam berbelanja di XYZ, temuan yang ada adalah bahwa konsumen punya kecenderungan untuk berbelanja pada urutan etalase yang tidak urut, pengambilan data dilakukan selama satu bulan dengan melakukan pengamatan terhadap 20 konsumen yang berbelanja dengan berpindah-pindah rak etalase. Kecenderungan yang terjadi adalah konsumen berbelanja pada etalase yang berubah-ubah secara signifikan dan kemudian kembali ke rak etalase semula untuk membeli barang berbeda. Kondisi tata letak etalase pada pusat perbelanjaan XYZ Puri dapat dilihat pada Gambar 1:

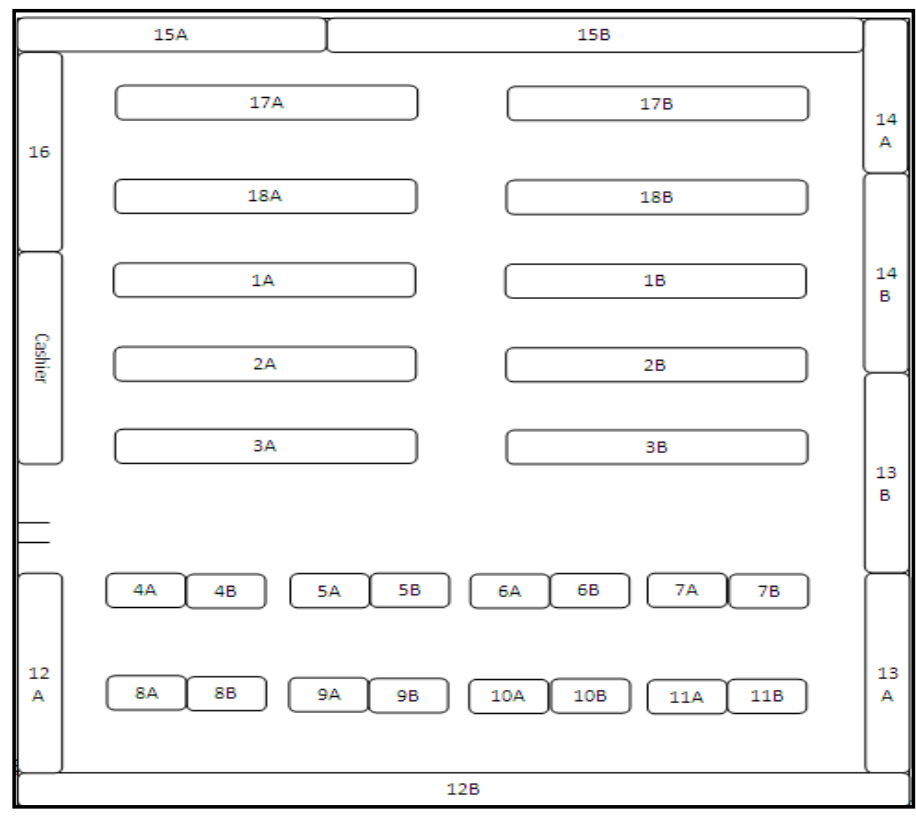

Gambar 1. Denah etalase. 
Agar ruang lingkup penelitian lebih jelas dan memiliki batasan masalah yang lebih bersifat fokus dan terarah, penelitian dibatasi pada aktivitas lalu-lintas belanja di tempat berbelanja XYZ Puri, pada hari Sabtu dan Minggu, pada waktu Sore dan Malam hari. Adapun yang menjadi alasan pemilihan hari dan waktu adalah karena pada hari dan waktu tersebut, XYZ Puri memiliki titik terpadat lalu-lintas berbelanja.

\section{Jasa}

Menurut Lovelock dan Wright, jasa merupakan tindakan atau kinerja yang menghasilkan manfaat bagi konsumen melalui perubahan yang diinginkan (Lovelock \& Wright, 1999:5). Ada empat hal pokok karakteristik dasar yang membedakan antara jasa dan barang (Fitzsimmons, 2001:22): (1) jasa bersifat intangible, sulit untuk diukur performance-nya (tidak dapat dilihat, dirasa, diraba, dicium, atau didengar sebelum dibeli) karena kriteria yang digunakan oleh konsumen untuk mengevaluasi kompleks dan sulit untuk didefinisikan; (2) jasa bersifat heterogen di mana performance-nya sering kali sangat bervariasi dan jarang terdapat standar yang bisa dijadikan acuan untuk memastikan keseragaman kualitasnya; (3) jasa bersifat inseparable, di mana antara produksi dan konsumsi sulit sekali dipisahkan; (4) jasa bersifat perishable, di mana jasa merupakan komoditi yang tidak dapat disimpan, tetapi ada pengecualian pada kasus tertentu jasa bisa disimpan, yaitu dalam bentuk pemesanan. Dari penjelasan mengenai teori di atas jelas terlihat bahwa mengadakan evaluasi dan monitoring terhadap kualitas sebuah usaha jasa akan lebih sulit dibandingkan dengan usaha barang atau produk. XYZ sebagai usaha yang bergerak dalam bidang jasa distribusi tentunya cukup sulit dalam melakukan evaluasi terhadap pelayanannya selama ini.

\section{METODE}

Penelitian melibatkan 20 orang konsumen yang berbelanja secara acak dan tidak ada perjanjian sebelumnya antara peneliti dengan konsumen. Kemudian mengamati pola alur belanja mereka dari rak ke rak dengan mengabaikan varian barang atau produk berbeda pada rak yang sama.

\section{Data Mining (Asosiasi)}

Data Mining merupakan teknologi yang sangat berguna bagi organisasi modern dalam menetapkan keputusan dan strategi perusahaan berdasarkan sekumpulan data yang tersimpan dalam gudang data mereka. Data Mining merubah paradigma banyak perusahaan tentang cara penyimpanan data dan memberdayagunakan data sebagai acuan penetapan strategi perusahaan (Veronika, S.M., 2002:47). Data Mining mengeksplorasi basis data untuk menemukan pola-pola yang tersembunyi, mencari informasi pemrediksi yang mungkin terlupakan oleh para pelaku bisnis.

Data Mining memiliki enam fungsi atau subkegiatan (Larose, D.T.,2005), yaitu: fungsi deskripsi, fungsi estimasi, fungsi prediksi, fungsi klasifikasi, fungsi pengelompokan, dan fungsi asosiasi

Dalam penelitian terhadap pola perpindahan konsumen pasar swalayan ini, perpindahan melibatkan objek perpindahan, yaitu etalase. Penelitian ini membahas bagaimana seharusnya pertimbangan terhadap pengaturan tata letak objek dan apakah ada hubungan antar objek, oleh karena itu fungsi Asosiasi digunakan dalam penelitian ini.

Asosiasi didasarkan pada Affinity Analysis, yaitu studi terhadap karakteristik atau atribut yang sering muncul bersama-sama. Affinity Analysis sering juga disebut sebagai Market Basket Analysis yang digunakan untuk mengungkap asosiasi di antara beberapa atribut yang masih tersembunyi. Analisis ini menghasilkan aturan (rules) yang diharapkan dapat mengungkap relasi antara dua atribut atau lebih. Rules yang dihasilkan akan berupa support dan confidence (Susanto, S., 2007:31). 
Association Rules akan berbentuk IF antecedent THEN consequent. Contoh dari 100 pelanggan yang berbelanja, kemudian 20 orang di antaranya membeli Mie Instant, kemudian di antara pembeli mie instant ini 5 orang di antaranya membeli Susu. Maka dari itu, aturan If beli mie instant, Then beli susu, memiliki nilai Support $=(5 / 100) \times 100 \%$ sama dengan $5 \%$, dan memiliki nilai Confidence $=(5 / 20) \times 100 \%$ sama dengan $25 \%$. Istilah teknis pertama yang harus kita kenal adalah item, yaitu barang yang dibeli atau objek yang menjadi objek kegiatan asosiasi, dalam kasus pembahasan adalah perpindahan antar rak etalase, sehingga Item disini adalah rak-rak etalase yang terdapat pada denah.

Himpunan item, dilambangkan dengan I, adalah himpunan dari semua jenis item yang akan dibahas, contoh-nya adalah:

$\mathbf{I}=\{17 \mathrm{~A}, 18 \mathrm{~A}, 1 \mathrm{~A}, \ldots ., 2 \mathrm{~A}, 3 \mathrm{~A}\}$

(Persamaan-1)

Himpunan item yang dikunjungi oleh responden ke- $i$ disebut transaksi ke- $i$, dilambangkan dengan $\mathrm{T}_{\mathrm{i}}$, sebagai contoh:

$\mathrm{T}_{1}=\{8 \mathrm{~A}, 8 \mathrm{~B}, 6 \mathrm{~A}, 11 \mathrm{~A}, 2 \mathrm{~B}\}$

$\mathrm{T}_{2}=\{5 \mathrm{~A}, 18 \mathrm{~A}, 17 \mathrm{~B}, 6 \mathrm{~A}\}$

$\cdot$

(Persamaan-2)

$\mathrm{T}_{20}=\{2 \mathrm{~A}, 1 \mathrm{~B}, 7 \mathrm{~A}, 3 \mathrm{~B}, 7 \mathrm{~A}\}$

Himpunan dari seluruh transaksi, dilambangkan dengan $\mathbf{D}$, sehingga:

$\mathrm{D}=\left\{\mathrm{T}_{1}, \mathrm{~T}_{2}, \ldots \ldots \ldots . \mathrm{T}_{20}\right\}$

(Persamaan-3)

Aturan asosiasi yang ingin dihasilkan akan memiliki implikasi sebagai berikut:

"Jika A maka B" atau " $A \Rightarrow B$ "

(Persamaan-4)

Dalam hal ini A disebutAnteseden sedangkan B disebut Konsekuen.

Sebagai catatan, pada aturan asosiasi yang kemudian akan dipergunakan, haruslah memenuhi dua sifat berikut ini.

Pertama adalah A dan B merupakan himpunan bagian murni.

$A, B \subset I$

(Persamaan-5)

Kedua, himpunan A dan $B$ adalah himpunan yang saling lepas.

$$
A \cap B=\phi
$$

(Persamaan-6)

Salah satu ukuran kinerja bagi aturan asosiasi “ $A \Rightarrow B$ ” adalah besaran support, dilambangkan dengan s $(A \Rightarrow B)$, didefinisikan sebagai:

$$
s(A \Rightarrow B)=P(A \cap B)=\frac{\text { Jumlahtransaksi yang mengandung item }- \text { item pada } A \cap B}{\text { Jumlahtotal transaksi pada } D} \text { (Persamaan-7) }
$$

Ukuran kinerja yang lain bagi besaran aturan asosiasi “ $A \Rightarrow B$ ” adalah besaran support, dilambangkan dengan $\operatorname{conf}(A \Rightarrow B)$, didefinisikan sebagai:

$$
\operatorname{conf}(A \Rightarrow B)=P(A \mathrm{I} B)=\frac{\text { Jumlah transaksi yang mengandung item }- \text { item pada } A \cap B}{\text { Jumlah transaksi yang mengandung item }- \text { item pada } A} \text { (Persamaan-8) }
$$

\section{HASIL DAN PEMBAHASAN}

Tabel 1 berikut merupakan hasil pengolahan data rute lalu lintas etalasi yang dikunjungi pembeli. 
Tabel 1

Rute Lalu-lintas Etalase

\begin{tabular}{|c|c|c|c|c|c|c|c|c|}
\hline \multirow{2}{*}{$\frac{\text { Rute }}{1}$} & \multicolumn{8}{|c|}{ Urutan Etalase yang Dikunjungi } \\
\hline & $3 B$ & $2 \mathrm{~A}$ & 2B & $1 \mathrm{~B}$ & $14 \mathrm{~B}$ & $1 \mathrm{~A}$ & $18 \mathrm{~A}$ & \\
\hline 2 & 3A & $5 \mathrm{~A}$ & 3B & $2 \mathrm{~A}$ & $2 \mathrm{~B}$ & $1 B$ & $1 \mathrm{~A}$ & \\
\hline 3 & $4 \mathrm{~A}$ & 4B & $8 B$ & $9 \mathrm{~A}$ & $5 \mathrm{~A}$ & 3A & $3 B$ & $2 \mathrm{~A}$ \\
\hline 4 & $3 B$ & $2 \mathrm{~A}$ & $1 \mathrm{~A}$ & $1 \mathrm{~B}$ & $4 \mathrm{~A}$ & & & \\
\hline 5 & 3A & 3B & 2B & 14B & $13 B$ & $2 \mathrm{~A}$ & & \\
\hline 6 & 3B & $2 \mathrm{~A}$ & $1 \mathrm{~A}$ & $18 \mathrm{~A}$ & 18B & $15 B$ & $15 \mathrm{~A}$ & \\
\hline 7 & $2 \mathrm{~A}$ & $2 B$ & $1 \mathrm{~A}$ & $18 \mathrm{~A}$ & 16 & & & \\
\hline 8 & $4 \mathrm{~A}$ & $8 \mathrm{~A}$ & $8 B$ & 12B & $9 \mathrm{~A}$ & $5 \mathrm{~A}$ & & \\
\hline 9 & $3 B$ & $2 \mathrm{~A}$ & $2 B$ & $1 \mathrm{~B}$ & $18 \mathrm{~A}$ & & & \\
\hline 10 & $4 \mathrm{~A}$ & $8 \mathrm{~A}$ & & & & & & \\
\hline 11 & $2 \mathrm{~A}$ & $2 B$ & $1 \mathrm{~A}$ & $18 \mathrm{~A}$ & 17B & & & \\
\hline 12 & $2 B$ & $1 \mathrm{~B}$ & $1 \mathrm{~A}$ & & & & & \\
\hline 13 & $2 B$ & $1 \mathrm{~B}$ & $2 \mathrm{~A}$ & $1 \mathrm{~A}$ & $18 B$ & 17B & & \\
\hline 14 & $3 B$ & $2 \mathrm{~A}$ & & & & & & \\
\hline 15 & $1 \mathrm{~B}$ & $2 \mathrm{~A}$ & & & & & & \\
\hline 16 & $2 B$ & $1 \mathrm{~B}$ & $1 \mathrm{~A}$ & 16 & & & & \\
\hline 17 & $3 B$ & $2 \mathrm{~A}$ & & & & & & \\
\hline 18 & $3 \mathrm{~A}$ & $3 B$ & $14 \mathrm{~A}$ & 17A & & & & \\
\hline 19 & $4 \mathrm{~A}$ & $8 \mathrm{~A}$ & 12B & $13 \mathrm{~A}$ & $6 \mathrm{~B}$ & & & \\
\hline 20 & 4B & $8 B$ & $9 \mathrm{~A}$ & $5 \mathrm{~A}$ & & & & \\
\hline
\end{tabular}

Adapun format tabulasi data aturan asosiasi tertera pada Tabel 2 berikut.

Tabel 2

Format Tabulasi Data Aturan Asosiasi

\begin{tabular}{ccccr}
\hline Itemset & \multicolumn{2}{c}{ Support } & \multicolumn{2}{c}{ Confidence } \\
\hline$\{3 \mathrm{~B}, 2 \mathrm{~A}\}$ & $8 / 20$ & $40 \%$ & $8 / 10$ & $80 \%$ \\
$\{2 \mathrm{~A}, 2 \mathrm{~B}\}$ & $7 / 20$ & $35 \%$ & $7 / 13$ & $53.85 \%$ \\
$\{2 \mathrm{~A}, 1 \mathrm{~A}\}$ & $7 / 20$ & $35 \%$ & $7 / 13$ & $53.85 \%$ \\
$\{2 \mathrm{~B}, 1 \mathrm{~B}\}$ & $7 / 20$ & $35 \%$ & $7 / 9$ & $77.78 \%$ \\
$\{2 \mathrm{~B}, 1 \mathrm{~A}\}$ & $7 / 20$ & $35 \%$ & $7 / 9$ & $77.78 \%$ \\
$\{1 \mathrm{~B}, 1 \mathrm{~A}\}$ & $6 / 20$ & $30 \%$ & $6 / 7$ & $85.71 \%$ \\
$\{2 \mathrm{~A}, 18 \mathrm{~A}\}$ & $5 / 20$ & $25 \%$ & $5 / 13$ & $38.6 \%$ \\
$\{2 \mathrm{~A}, 1 \mathrm{~B}\}$ & $5 / 20$ & $25 \%$ & $5 / 13$ & $38.6 \%$ \\
$\{3 \mathrm{~B}, 2 \mathrm{~B}\}$ & $4 / 20$ & $20 \%$ & $4 / 10$ & $40 \%$ \\
$\{3 \mathrm{~B}, 1 \mathrm{~B}\}$ & $4 / 20$ & $20 \%$ & $4 / 10$ & $40 \%$ \\
$\{3 \mathrm{~B}, 1 \mathrm{~A}\}$ & $4 / 20$ & $20 \%$ & $4 / 10$ & $40 \%$ \\
$\{2 \mathrm{~B}, 18 \mathrm{~A}\}$ & $4 / 20$ & $20 \%$ & $4 / 9$ & $44.44 \%$ \\
$\{1 \mathrm{~A}, 18 \mathrm{~A}\}$ & $4 / 20$ & $20 \%$ & $4 / 10$ & $40 \%$ \\
$\{3 \mathrm{~B}, 18 \mathrm{~A}\}$ & $3 / 20$ & $15 \%$ & $3 / 10$ & $30 \%$ \\
$\{3 \mathrm{~A}, 3 \mathrm{~B}\}$ & $3 / 20$ & $15 \%$ & $3 / 4$ & $75 \%$ \\
$\{4 \mathrm{~A}, 8 \mathrm{~A}\}$ & $3 / 20$ & $15 \%$ & $3 / 5$ & $60 \%$ \\
\hline
\end{tabular}

Aturan asosiasi yang memenuhi batasan $\min$ (support) $=30 \%$, dan $\min$ (confidence) $=70 \%$, tertera pada Tabel 3. 
Tabel 3

Daftar Aturan Asosiasi yang Memenuhi Syarat

\begin{tabular}{ccccc}
\hline Itemset & \multicolumn{2}{c}{ Support } & \multicolumn{2}{c}{ Confidence } \\
\hline$\{3 \mathrm{~B}, 2 \mathrm{~A}\}$ & $8 / 20$ & $40 \%$ & $8 / 10$ & $80 \%$ \\
$\{2 \mathrm{~B}, 1 \mathrm{~B}\}$ & $7 / 20$ & $35 \%$ & $7 / 9$ & $77.78 \%$ \\
$\{2 \mathrm{~B}, 1 \mathrm{~A}\}$ & $7 / 20$ & $35 \%$ & $7 / 9$ & $77.78 \%$ \\
$\{1 \mathrm{~B}, 1 \mathrm{~A}\}$ & $6 / 20$ & $30 \%$ & $6 / 7$ & $85.71 \%$ \\
\hline
\end{tabular}

\section{PENUTUP}

Dengan perhitungan Data Mining, di mana menggunakan fungsi Asosiasi dan mengacu kepada aturan main dan tetapan standard dari Asosiasi. Diperoleh sebuah himpunan dari objek-objek penelitian, objek-objek tersebut memiliki rute dan pola atau siklus. Responden dalam penelitian ini mewakili banyaknya rute antar objek. Etalase didefinisikan sebagai objek perpindahan setiap responden. Kemudian dari rute-rute yang terbentuk, diperoleh suatu pola dan hubungan atau asosiasi antar objek. Data pada Tabel 3 memperlihatkan bahwa apabila letak etalase pada kolom itemset diletakkan dengan jarak yang ergonomis untuk dijangkau (perlu studi dan kajian tersendiri untuk mengetahui jarak yang paling relevan), sehingga konsumen pada pasar swalayan akan lebih menghemat tenaga dan waktu mereka dalam perpindahan dalam mencari produk antar etalase (produk di setiap etalase diperhitungkan tetap berada pada etalase yang sama pada saat ada perpindahan layout etalase). Dalam perkembangannya, penggunaan algoritma alternatif dengan koridor yang sama juga dimungkinkan untuk membuat komparasi antar algoritma. Berry dan Browne dalam bukunya berjudul Lecture Notes in Data Mining (Berry dan Browne, 2006) memberikan paparan tentang penggunaan algoritma sejenisnya, yaitu: Generalized Association Rules Algorithm, Quantitative Association Rule Algorithm, dan Asynchronous Parallel Mining Algorithm.

\section{DAFTAR PUSTAKA}

Berry, M.W. \& Browne, M. (2006). Lecture Notes in Data Mining. Singapore: World Scientific.

Fitzsimmons, James A. \& Fitzsimmons, Mona J. (2001). Service Management: Operations, Strategy, Information Technology ( ${ }^{\text {rd }}$ edition). New York: McGraw-Hill.

Larose, D.T. (2005). Discovering Knowledge in Data: an Introduction to Data Mining. New Jersey: John Wiley \& Sons.

Lovelock, C.H. and Wright, L. (1999). Principles of Service Management and Marketing. New Jersey: Prentice-Hall.

Susanto, S. (2007). Data Mining: Mengenal Fungsi Utama dalam Klasifikasi, Clustering dan Association Rule. Bandung: Parahyangan Catholics University.

Veronika, S. M. (2002). Data mining sebagai solusi bisnis. Jurnal Integral, 7(1). Parahyangan Catholics University, Bandung, Indonesia. 